DE DE GRUYTER

OPEN
Journal of Intercultural Management

Vol. 5, No. 3, September 2013, pp. 63-73

DOI 10.2478/joim-2013-0019

Joanna Małgorzata Michalak

University of Lodz

Robert J. Ristino

Clark University

\title{
A Phenomenological Study of Employee Perceptions of Managerial Behaviors as Personal Enactments of Organizational Culture
}

\begin{abstract}
Using a phenomenological methodology, this research study examines the phenomenon of organizational culture through the perceptions of those who experience it. Rather than studying how organizational culture affects organizational behavior and success, the researchers focus on employee perceptions of culture as a consequence of experiences with managerial behaviors as personal enactments of culture. The notion of personal enactments is drawn from the work of Edgar Schein. Schein [1985] has identified three levels of organizational culture: artifacts, values and beliefs. Among artifacts, Schein identifies the personal enactments of organizational values by senior managers as one of the more important.

The researchers derived the data describing these personal enactments from 20 volunteer subjects reporting in self-administered questionnaires their experiences with managerial behaviors. Respondent perceptions are described in their own words, conveying their understandings, feelings, emotions and behaviors. Responses are categorized into units of relevant meaning, organized into clusters of similar meaning and then into themes. From these themes the researchers draw some insights and understanding of how system actors both live and experience culture in an organizational setting.
\end{abstract}

Key words: organizational culture, managerial behaviors, employee perceptions, organizational phenomenology, organizational ethnography 


\section{Introduction}

Organizational culture researchers have historically focused their research attention on the macro level of analysis examining how various aspects of culture influence both system success and the behavior of actors in those systems. One research area that has not been addressed is a micro level analysis of how those system actors engage with and experience organizational culture and how those experiences influence their work lives. Also, researchers have become increasingly aware of the need to join the micro and macro levels of analysis to improve our understanding of organizational phenomena [Franklin J. L., 1973, 1975; Likert R., 1961, 1967; Moss-Kanter R., 1983; Mudrack P.E., 1989].

This paper reports on the preliminary results of a qualitative study that addresses that need by examining engagements with organizational culture from the perspective of those engaging with the culture. Examining such a phenomenon requires a methodology that focuses on the cognitive experiences of the organizational actor, denuded of any preconceptions or biases of the researcher. Simply, let the words of the actors describe how they experience organizational culture and how that experience shapes and defines their work life.

\section{Methodology}

Among these qualitative methodologies are organizational ethnography and phenomenology. While ethnography is based on data collection through physical presence of the researcher and as such represents his or her perceptions [Eberle T.S. and Maeder C., 2011, p. 54], we have chosen a phenomenology perspective because it explicitly focuses on identifying perceptions that real members of an organization create as they experience a phenomenon in a given situation [Lester S., 1999, p. 1]. Moreover, as Husserl [1970] notes, in phenomenology's purest form, it attempts only to describe and not explain phenomena and consequently is free of researcher influence.

While the authors have adopted a phenomenological approach as their primary research methodology they have adapted to some extent that technique for the purposes of this research project. Specifically, they have altered both the traditional phenomenological interview technique as described by Hycner [1985] for obtaining data and the methodology of categorizing subject perceptions.

Traditionally, a researcher interviews subjects and those interviews are recorded. Recordings are then transcribed and „units of general meaning” and "units of relevant meaning" identified to provide an in depth understanding of the perceptions, thoughts and meanings ascribed to the phenomenon by the subject [Hycner R.H., 1985, pp. 280-290]. Hycner [1985, p. 282] defines 
units of general meaning as „words, phrases, non-verbal or paralinguistic communications which express a unique and coherent meaning clearly differentiated from that which precedes and follows". Units of relevant meaning are identified by addressing the research question to the units of general meaning to determine whether the subjects' responses illuminate to any extent the research question [Hycner R.H., 1985, p. 284]. These units are then aggregated into clusters comprising units of similar meaning.

In contrast, the authors of this study have employed a written self-report technique requiring subjects to complete an in-depth questionnaire rather than using the traditional interview technique. A quantitative technique, content analysis, was then used to both categorize and quantify in an Excel spreadsheet various subject responses to the phenomenon under study. Lester [1999] explains that a major difficulty in phenomenological research is that large amounts of data are created for analysis. Consequently, he suggests creating some form of database to allow for easier manipulation of the data [Lester S.,1999, p. 2].

Following a traditional phenomenological research approach, the verbatim responses were deconstructed to identify units of general meaning and then units of relevant meaning [Hycner R.H., 1985, pp. 282-286]. These were entered into the database and then organized into clusters for explication. Employing a content analysis technique proved less cumbersome and time consuming for analyzing subject responses than other techniques we explored.

1. The study's self-report survey instrument comprised 10 content questions and eight demographic questions. For the purposes of this preliminary report only two questions that addressed managerial behaviors as a reflection of personal enactment are reported in this paper. The analysis of the entire study will be reported in a future article. The two questions reported in this study are:Please think about your manager and his or her personal behavior on the job. Then describe these behaviors and your thoughts and feelings about them.

2. When you first began your current job, please recall the way you got familiar with (1) how the organization functions; (2) rules of formal and informal relationships among employees; and (3) your new work areas, work duties, tasks, and responsibilities that needed to be accomplished.

Using a codebook, the researchers independently coded the verbatim narratives to the first question as either positive or negative. If there were disagreement as to coding, the researchers would review their findings and work toward consensus. There were no coding disagreements. Each was also coded for having a positive or negative effect on the respondent and whether that effect was cognitive, resulting in new knowledge or understanding; affective, 
creating feelings and emotions; or behavioral, motivating action. Responses to the second question were categorized simply by calculating frequencies of those identified as agents for information transfer.

\section{Research Question}

The purpose of this study was to understand the phenomenon of how organizational actors experience and give meaning to culture as they observe and interact with managerial behaviors. Schein [1985] has identified threelevels of culture existing in an organization: artifacts, values and basic assumptions. This paper examines engagements with one dimension of the artifacts level that of managerial behavior or what Schein [1985] refers to as „personal enactment”. While Schein uses the phrase "personal enactment” to refer to the behaviors of senior managers that reflect specific aspects of organizational culture [Nelson D.L. and Quick J.C., 2000, p. 533], we also apply the term to managers at the subsystem level of the organization. It is our belief, described in our Competent Culture model [Michalak J.M. and Ristino R.J., 2012], that subsystem cultures have a symbiotic relationship with organizational cultures and that managers, through their behavior, significantly influence either positively or negatively those subsystem cultures.

In addition, as role models managers play an important system function as transmitters of culture to organizational members [Nelson D.L. and Quick J.C., 2000, p. 534], a role that Vygotsky [Trevarthen C., 1988] would describe as „agents of culture." In his pedagogical theories, Vygotsky argued that a child's behavior occurs within the framework of the caregiver's cultural knowledge [Travethern C., 1988]. Just as caregivers transfer cultural knowledge to the child, so managers transfer cultural knowledge to those who work under their supervision. Simply, an agent of culture is any system actor responsible in an organizational domain for controlling information production, access and distribution [Ristino R.J., 2008, p. 60]. Through their personal enactments as agents of culture, managers both reflect and help shape employee perceptions of organizational culture. This leads to our research question:

"What are the cultural perceptions and behavioral outcomes of organizational actor experiences with managerial behaviors?"

\section{Sampling Methodology}

To address this question, we selected a small group of volunteers to serve as our sample. Neither the size of the sample nor the technique used for recruiting the sample are methodological issues since the validity of data is in the content itself and not a function of either the number of cases examined or of how the cases were selected. In fact, a phenomenological study could involve just one 
subject and still be considered valid since the results of that study remain true for that individual as sample size is ,irrelevant” [Englander, 2012, p. 20].

According to Boyd [2001] between two and 10 participants are more than sufficient for a meaningful phenomenological study while Cresswell [1998, pp. 65 and 113] agrees that 10 should be the upper limit. However, as a minimum, Englander [2012, p. 23] recommends at least three subjects. That number would itself generate a considerable amount of interview data. Experience has shown that when additional cases are added to the study the data becomes redundant and superfluous. However, since our data collection methodology differs from standard phenomenological practice, affecting perhaps negatively the volume of data, we opted to collect self-assessments from 20 subjects to ensure sufficient data for analysis. Furthermore, as Englander notes, a greater number of subjects may give you a ,better appreciation of the variation of the phenomenon" [Englander E.M. , 2012, p. 21].

In a phenomenological study the only constraint on subject selection is the requirement that the subject have experience with the phenomenon under study. This required that all volunteers in the study be currently or recently employed. Moreover, since the results of phenomenological studies are not intended to be representative of the population as a whole, nonprobabilitysampling techniques are used. Consequently, we chose two well established nonprobability research sampling techniques: convenience and snowball sampling. With convenience or accidental sampling the researcher merely chooses subjects that are easily at hand and that are willing to participate in the study. Snowball sampling uses research subjects to identify or recruit others with similar characteristic or knowledge of the phenomenon to participate in the study [Bailey K. D., 1978, pp. 81-83].

Our convenience sample comprised volunteers from a group of some 60 part-time graduate students at a Central European university, as well as a small number of other graduate students recruited using the snowballing technique. All of the subjects were currently or had recently been employed. Subjects ranged in age from 24 to 37 with 14 female and 6 male. They represented nine countries and were employed at companies ranging in size from between five to $500+$ employees. Eight of the companies were international in scope.

\section{Ethics}

Both researchers in this study were very sensitive to the ethical requirements involving human subjects. To address ethical concerns, we used informed consent to ensure that all participants were well aware of the purpose of the study and the credentials of the researchers [Bailey K.D., 1978, pp. 384-385]. While we did not administer an Informed Consent Form, we did ensure through an oral presentation that all participants were aware of all of the following: 
1. An understanding of the purpose of the study, how it would be conducted, and identification of those who would be administering the survey instrument.

2. A description of the benefits to be obtained from the research for those employed in organizational settings.

3. An offer to answer any questions concerning the procedures at any time.

4. An instruction that participation is purely voluntary and subjects can withdraw from participation at any time during the study without prejudice.

5. A reassurance that the identities of all participants would be kept absolutely confidential and that demographic data would be kept general and nonspecific to avoid identifying participants.

6. Explanation of how the results of the research project would be used and made public.

\section{Explicitation of the Data}

The term „explicitation” we borrow from Hycner [1999, p. 161] who warns against use of the phrase "data analysis” since "the term (analysis) usually means a „breaking into parts” and therefore often means a loss of the whole phenomenon...[whereas „explicitation” implies an]...investigation of the constituents of a phenomenon while keeping the context of the whole." Consequently, in the explicitation we will avoid analyzing or interpreting what the data is telling us but rather convey the data as explicitly stated by the respondents. We will, however, aggregate and relate that data when relationships are apparent. When we complete the explicitation of data, we will share our observations and thoughts on the results of this study.

\section{Units of Relevant Meaning, Clusters and Themes}

Our review of the 20 cases identified 104 units of relevant meaning for Question 1. These were organized into five clusters: (1) Management Style, (2) Communication Style, (3) Personality Traits, (4) Decision Making, and (5) Organizational Climate. This is the step in the phenomenological process that is far more art than science. The cluster with the largest number of units of relevant meaning was Management Style with 46 followed by Organizational Climate with 23, Personality Traits, 19, Communication Style, 12 and, finally, Decision Making, 4.

Naturally, organizing these clusters involved our own judgment and creativity. Coailizzi [1978, p. 59]. explains how the phenomenological researcher is "engaged in something which cannot be precisely delineated, for here he is involved in that ineffable thing known as creative insight". Nevertheless, we believe that most researchers reviewing our data would have arrived at a similar number of like clusters. 
Our next step was to see if the clustering of units of relevant meaning led us to some naturally occurring themes. One that immediately appeared was that „Management Style," reflected in both behavior and affect, appears to be the most potent influencer of employee perceptions of managerial behavior. A second theme is the effect that „Management Style," in concert with both "Communication Style" and "Decision Making” informs employee perceptions of "Organizational Climate." The last theme refers to the disturbing finding that negatively viewed managers rarely are identified as being significant transmitters of organizational knowledge to their employees.

While most of the cluster titles are self explanatory, „Organizational Climate" can be interpreted and defined in innumerable ways. So for the sake of clarity we use Moran and Volkwein's [1992, p. 20] broad and inclusive definition for organizational climate:

Organizational climate is a relatively enduring characteristic of an organization which distinguishes if from other organizations: and (a) embodies members collective perceptions about their organization with respect to such dimensions as autonomy, trust, cohesiveness, support, recognition, innovation, and fairness; (b) is produced by member interaction; (c) serves as the basis for interpreting the situation; (d) reflects the present norms, values and attitudes of the organization's culture; and, (e) acts as a source of influence for shaping behavior.

In summary, we view climate as a metaphor for the extent to which an organization is perceived as supportive of its members. It represents the psychological environment of an organization. It is a product both of the organization's culture and the interaction of system actors as they experience that culture. Moran and Volkwein [1992, p. 39] sum up the culture-climate relationship by describing climate as a "created response which an interacting group of individuals, who are informed and constrained by a common organizational culture, make to the demands and contingencies arising in the organization's internal and external environments".

Respondents comments appear to indicate that perceptions of management behavior described in the "Management Style," "Communication Style" and "Decision Making" clusters, influence the state of the organizational climate in their units, resonating either positively or negatively with the organization's culture. Moreover, these perceptions also influence the respondents overall view of the organization's culture as reflected in the organization's climate.

The "Communication Style" cluster is descriptive of the degree to which managers are open to communicating freely with their employees, referred to as two-way communication. It implies a readiness to share information; to listen and be responsive to employee concerns, issues and suggestions; and, as reported in the „Decision Making” cluster, to share power in decisions that influence their work lives. 
For example, in Case 2, the manager's leadership style was described as „doesn't like to interact with team members" and the climate characterized as „miscommunication can affect our job satisfaction.” In Case 3, the respondent described the manager as always giving "clear and direct instructions" and the climate was described as „felt comfortable working there.” In Case 11, the manager was described negatively as „rather emotional” and that „she should be more of a decision-maker." Such relationships among and between clustered units of relevant meaning were consistent throughout the data. In other words, positive perceptions of management behavior were reflected in positive perceptions of organizational climate and negative perceptions of management behavior were similarly reflected in negative perceptions of organizational climate. These findings would not have been possible if we had selected a smaller number of subjects. The size of the study allowed us to see variations in the data that were only apparent with a larger sample size, as Englander noted [2012].

When we examined the Management Behavior Experience (MBE), coded as positive, we see a natural relationship between positive $\mathrm{MBE}$ and positive clusters of units of relevant meaning. The data appears to support the intuitive belief that employees have positive experiences with manager behaviors when they view the manager's management style and personality positively. These positive perceptions are framed in comments such as "best manager I ever met," „behavior was ethical," „he generally helps me at every inquiry at work,” „patient and caring,” „attentive to me,” „open attitude,” and „well educated and eager to help everyone."

The relationship between "Management Style” and "Personality Traits” is also informative. When you find respondents characterizing managerial behaviors in positive language, such as "charismatic," it was often associated with the respondent reporting positive „Personality Traits,” such as „very enthusiastic, caring, and self-confident."

The same also holds true for negative MBE and negative clusters of units of relevant meaning. In fact, of the 20 cases, 11 were coded as negative experiences. Typical negative comments included such phrases as „she does not care for her employees," „most of the time at her office,” „doesn't like to interact with team members," „very authoritative,” „communication with him was very difficult," „my manager is a hothead," and „unequal treatment of employees."

As agents of culture, managers transfer through their behaviors the organizational culture to members of their work team. This role was addressed in our second question regarding „Knowledge Transference” in the organization. The data generated by this question suggests that when managerial behaviors are viewed as negative, their role as transmitters of knowledge to team members 
is either greatly diminished or non-existent. In eight of the 11 cases in which employees reported negative management behaviors, respondents did not identify the manager as their source for information about the organization. Instead, most identified either „co-workers,” „employee handbook,” or „oneself” as the source of information. Similar responses were recorded for transference of knowledge for organizational rules, and job duties and responsibilities.

When it came to discussing specific aspects of culture in responding to question one, such as values and beliefs, respondents only identified one value and only in three of the cases. Only when specifically asked about organizational values, did they respond to the issue of values. However, in cases in which they alluded to values, the one identified was „respect.” The term, it should be noted, was used mostly in the context of „respect” for employees. What is interesting to note is that in all cases when "respect” was identified, it was in the context of a positive description of experiences with managerial behaviors. For example, Case 16, in which the respondent reported, „He treats his employees with respect."

\section{Discussion}

In reviewing the data, it is apparent that managers play a significant role in influencing employee perceptions of organizational life. It is also apparent, and a bit disconcerting, that so many employee experiences with managerial behaviors tend to be negative. Moreover, it appears that rather than fulfilling one of their most significant organizational roles - transmitting and nurturing organizational culture at the subsystem level - they have abdicated that important role to other sources.

As we read the verbatim comments from the respondents, there is a sense that good managers have an intuitive understanding of how to make connections with people; how to communicate openly and honestly; how to manage and mentor those around them; and how to create a wholesome and uplifting organizational climate. But poor managers, and from this study, too many abound, seem completely lost at sea, unable or unwilling to deal with the turbulence of organizational life. They tend to insulate themselves from their staff, communicate poorly, lead indifferently, and often reflect the very worst image of an organization. These behaviors, no doubt, reflect and help create a culture that can either be supportive or destructive. If a manager is open and engaging with her employees or closed and aloof, what does it communicate to their staffs about the organization's norms, values and beliefs?

The last implication of this study is that in work environments managers can and often do play a significant role in creating a wholesome organizational climate. When that climate is positive and supportive it further nurtures and reinforces organizational culture. When negative, the opposite is true. From 
our study we can assume that managers, through their specific managerial behaviors, reflect and reify the culture of the organization. If they respect their employees, then employees will see the organization as having respect for them. It is interesting to note, as reported earlier, that only in Cases 3, 16 and 19 did respondents identify a specific value - respect - when commenting on „Management Style.” In all those cases the experience with manager behaviors was viewed as positive as was the climate. It is likely that the employee will continue to believe that the organization follows and supports its own values when its managers do. Such employee experiences serve to strengthen organizational climate and culture. In an earlier paper we identified such cultures as competent, having congruency between system and subsystem cultures. This congruency leads to intra-organizational cooperation and effectiveness by creating environments that nurture organizational success [Michalak J.M. and Ristino R.J., 2012].

\section{A Final Observation}

Based on the study's results, we posit that senior management can only ensure the competency of its organizational culture by hiring and promoting to management positions only those who have, in author Tom Wolfe's words, the right stuff, not only to lead but to believe in and nurture the organization's values and beliefs. This means not only seeking individuals who have the right education, training and experience in management, but who have the right psychological makeup: self-confident, outgoing, engaging, optimistic, communicative, thoughtful, fair and levelheaded. Identifying those with the right stuff may be senior management's most important and challenging task of the future.

\section{Bibliography}

Bailey, K. D. (1978) Methods of Social Research, New York, N.Y.: The Free Press

Boyd, C.O. (2001) Phenomenology the Method in P.L. Munhall (Ed.), Nursing Research: A Qualitative Perspective, $3^{\text {rd }}$ edition, Sudbury, MA: Jones and Bart冈lett

Cresswell, J.W. (1994) Research Design: Qualitative and Quantitative Approaches, Thousand Oaks, CA: Sage

Englander, E.M. (2012) The Interview: Data Collection in Descriptive Phenomenological Human Scientific Research, Journal of Phenomenological Psychology, No. 43

Eberle T.S., Maeder C. (2011) 'Organizational Ethnography' in D. Silverman (Ed.), Qualitative Research, 3rd edition, SAGE Publications Ltd, London

Franklin, J. L. (1973) A Path Analytic Approach to Describing Causal Relationships Among Social Psychological Variables in Multi Level Organization, unpublished Doctoral thesis, The University of Michigan 
Groenewald, T. (2004) A Phenomenological Research Design Illustrated, International Journal of Qualitative Methods, 3 (1), April, pp. 1-26

Husserl, E. and Trans D. Carr (1970) Logical Investigation,. New York: Humanities Press.

Hycner, R.H. (1985) Some Guidelines for the Phenomenological Analysis of Interview Data. Human Studies, 8, pp. 279-303

Lester, S. (1999) An introduction to phenomenological research, Tauton, UK: Stan Lester Developments

Likert, R. (1961) New Patterns of Management, New York: McGraw-Hill

Michalak, J.M., Ristino, R.J. (2012) 'The Competent Culture Paradigm: An Alternative to the Strong Culture Hypothesis' Journal of Intercultural Management, vol. 4, no. 4, December, pp. 70-84.

Moss-Kanter, R. (1983) The Changemasters, New York: Random House

Mudrack, P.E. (1989) Group cohesiveness and productivity: A Closer Look, Human Relations, 42 (9), pp. 771-785

Moran, E.T. and Volkwein, J.F. (1992) The Cultural Approach to the Formation of Organizational Climate, Human Relations. Sage Publications, vol. 45, no. 19, pp. 1947.

Nelson, D. L. and Quick, J.C. (2000) Organizational Behavior. Cincinnati, OH: SouthWestern College Publishing

Ristino, R. J. (2008) The Sociocultural Model of Public Relations/Communications Management Practice: A Critical-Cultural Perspective, International Journal of Strategic Communication. Routledge, Vol. 2, No. 1, pp. 54-73

Schein, E. H. (1985) Organizational Culture and Leadership: A Dynamic View. San Francisco: Jossey-Bass Publishers

Trevarthen, C. (1988) 'Universal cooperative motives: how infants begin to know language and culture of their parents' in G. Jahoda and I.M. Lewis (Eds.), Acquiring Culture: Cross Cultural Studies in Child Development, London: Croom Helm 